\title{
Study of the characteristics of soil surfaces as roads for agricultural robotic complexes
}

\author{
Sergey Zhukov¹, Vladimir Belyakov², and VladimirMakarov,* \\ ${ }^{1}$ Nizhny Novgorod State Engineering and Economic University, 606340 Nizhny Novgorod region, \\ Knyaginino, Russia \\ ${ }^{2}$ Nizhny Novgorod State Technical University n.a. R.E. Alekseev, 603950, Nizhny Novgorod, Russia
}

\begin{abstract}
The article is devoted to the study of using mobile robotic systems in agriculture. It is shown that it is necessary to know the physical and mechanical characteristics of the main support motion surfaces to calculate the mobility and efficiency of these complexes. This will allow calculating the movement resistance and traction force, and as a result, choosing the best appliance design for these conditions. Typical areas of agricultural land near the village of Belka in the Knyaginino district of the Nizhny Novgorod region were analyzed. More than 200 measurements were made. The dependencies for calculating the main soil parameters are described. It is obtained that the average values of the soil parameters change within the following limits: the deformation modulus is 15.5-23 $\mathrm{N} / \mathrm{cm}^{2}$, the specific soil adhesion is $13.9-16.7 \mathrm{kPa}$, the internal friction angle is $14.8-16.4$ degrees, the density is $1.09-1.14 \mathrm{~g} / \mathrm{cm}^{3}$, the soil moisture is $035-16,9 \%$.
\end{abstract}

\section{Introduction}

Modern technology of agricultural production implies the presence of a human operator of agricultural machinery in the general technological chain. The exclusion of human beings from the technological chain of agricultural production significantly expands the possibilities for improving the quality of agricultural products.

Currently, agricultural technological methods are based on two principles: 1) intensification of agricultural production; 2) the principle of energy saving while manufacturing agricultural products.

Robotic means of agricultural mechanization allow intensifying technological processes based on all-weather conditions and round-the-clock operation. The exclusion of comfort and life support systems for human workers can significantly increase the level of energy efficiency of technological processes in the agricultural production.

The agricultural sector is divided into several branches, and the two most important are crop growing and animal husbandry. They comprise the largest human and mechanical resources. The territory of agricultural enterprises is constantly increasing, the number of cultivated land is growing, which is why the demand for professional personnel and equipment is increasing, too. At the same time, the growing expenses need to be reduced.

\footnotetext{
${ }^{*}$ Corresponding author: makvl2010@gmail.com
} 
This can be done by including automated systems in agriculture. A robot can replace several people, and a group of such mechanization tools can be controlled by 2-3 operators.

In order for robotic systems to be most effective, their chassis must have the best mobility in the conditions where they will be operated. In other words, one of the aspects of the effectiveness of the robotic systems use in agriculture consists in the interaction of the chassis mover with the motion surface. To do this, it is necessary to know the physical and mechanical parameters of the soil, as well as the nature of their distribution for typical traffic conditions.

\section{Location of the research}

For measurements, characteristic areas near the village of Belka, Knyaginino district of the Nizhny Novgorod region were selected. They are the property of Novy Vek LLC (Belka village council). Areas of agricultural land were studied from the position of the possibility of mobile robotic complex (MRC) movement.

Characteristic zones of the area were studied, such as a ploughed field and a fallow field, a virgin land, a dirt road and a road compacted with rubble. In this article, the study of one location is considered in detail. Figure 1 shows a field of 106.1 Hectares total area, located in the North-East of the village of Belka. The soil type is loam. It is situated on a slope, its lower part approaches the Ulynovka river. It is currently fallow field. Figure 1 shows the zones where the measurements were made. Figure 2 shows the photo examples of the selected sections.

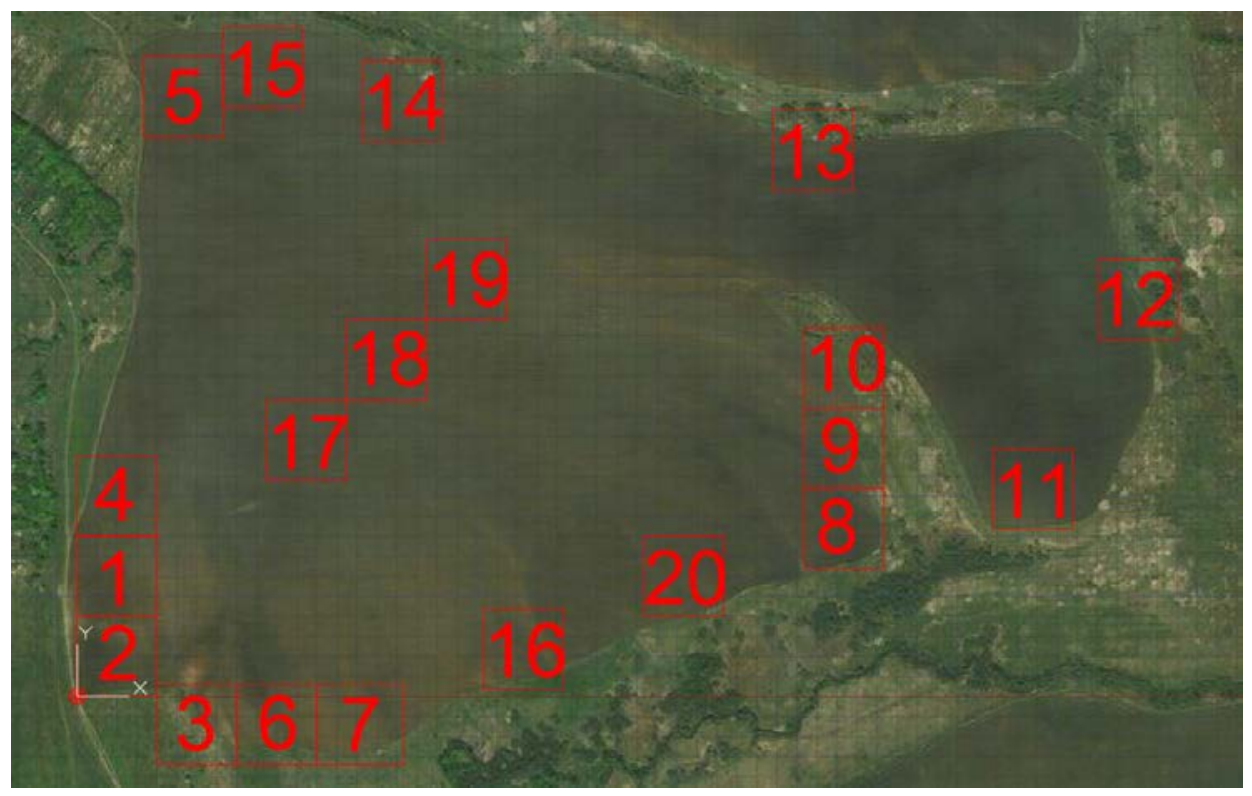

Fig. 1. Map of the studied field obtained using Yandex.Maps service showing the sections where the measurements were made 

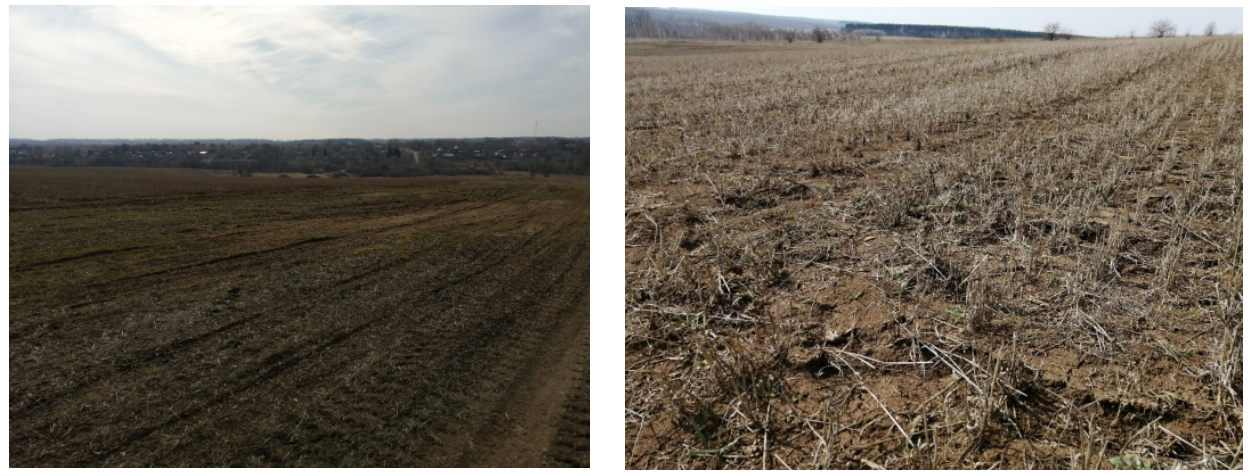

Fig. 2. Examples of the studied field sections.

\section{Appliances for conducting experiments}

The equipment used were a ground penetrometer PG-1; a clock indicator of IC-type; compact electronic scales; a GPS tracker; "Litvinov field laboratory" PLL-9. All measurements were performed in accordance with GOST 5180-84 and the operating instructions [1, 2].

For each of the 20 selected locations, the indicator reading was measured (S, mm), as well soil samples were taken for measurement. The readings of the penetrometer indicator are determined by obtaining an average value based on the results of 5-10 measurements at the points located at a distance of at least $10 \mathrm{~cm}$ from each other.

Using the measurement results of the penetrometer indicator with the help of the conversion charts one obtains the required for the further calculation parameters of the MRC mobility: deformation modulus, internal friction angle, cohesion coefficient in the soil.

Figure 3 shows the moment when the penetration force and soil density are measured.
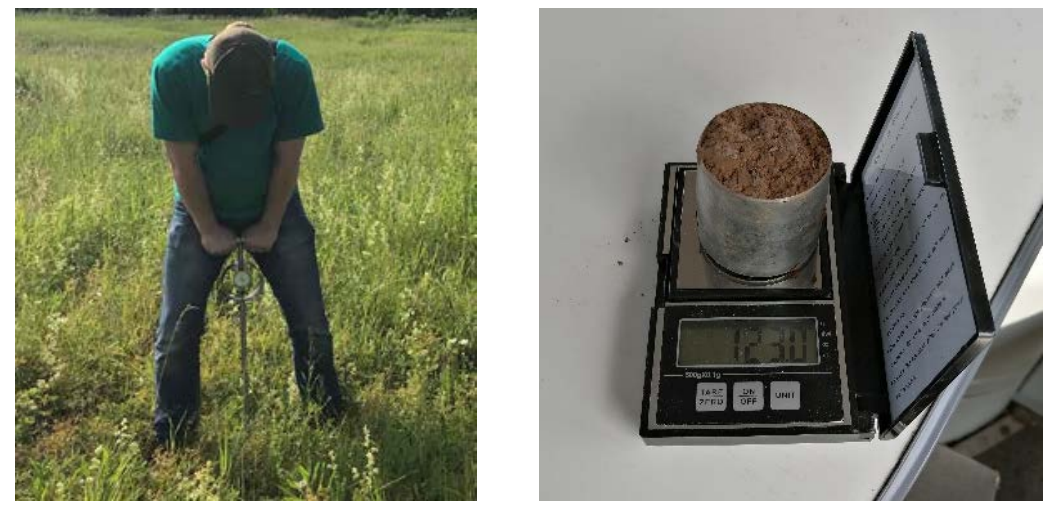

Fig. 3. Examples of measuring the penetration force (on the left) of weighing the measured volume of soil.

The main dependencies for calculating the studied parameters look as follows:

- penetration force $P=k_{S} S$,

- penetration resistance $E_{w}=k_{i} P$,

- deformation modulus $E_{\mathrm{y}}=k_{E} E_{w}+E_{\mathrm{y} 0}$,

- internal friction angle $\varphi_{г р}=\varphi_{г р}+k_{\varphi} E_{w}$, 
- cohesion coefficient $C=C_{0}+k_{C} E_{w}$,

- soil density $\rho=m V_{0}^{-1}$,

- soil moisture $W=\left(m-m_{1}\right) m_{1}{ }^{-1}$,

where $k_{S}, k_{i}, k_{E}, k_{\varphi}, k_{C}$ - the empirical coefficients [3,4], $m$ - mass of the measured volume of soil in its natural state, $V_{0}$ - soil volume, $m_{1}$ - mass of soil in a dry condition.

Measurements of soil characteristics were entered in the table. Examples are shown in table 1.

Table1. Measured soil characteristics.

\begin{tabular}{|c|c|c|c|c|c|}
\hline $\begin{array}{c}\text { Location } \\
\text { number }\end{array}$ & $\begin{array}{c}\text { Coordinates } \\
\text { (latitude/longitude) }\end{array}$ & $\begin{array}{c}\text { Height above } \\
\text { sea level, } \mathrm{m}\end{array}$ & $\begin{array}{c}\text { Indicator } \\
\text { reading } S, \mathrm{~mm}\end{array}$ & $\begin{array}{c}\text { Mass } \\
\mathrm{m}, \mathrm{g}\end{array}$ & $\begin{array}{c}\text { Mass } \\
\mathrm{m}_{1}, \mathrm{~g}\end{array}$ \\
\hline 1 & $\begin{array}{c}55^{\circ} 45^{\prime} 34.484^{\prime \prime} \\
45^{\circ} 8^{\prime} 51.324^{\prime \prime}\end{array}$ & 140 & 17 & 5,6 & 4,8 \\
\hline 2 & $\begin{array}{c}55^{\circ} 45^{\prime} 28.066^{\prime \prime} \\
45^{\circ} 8^{\prime} 57.473^{\prime \prime}\end{array}$ & 130 & 15 & 5,3 & 4,2 \\
\hline 3 & $\begin{array}{c}55^{\circ} 45^{\prime} 28.408^{\prime \prime} \\
45^{\circ} 9^{\prime} 4.010^{\prime \prime}\end{array}$ & 125 & 25 & 6,2 & 5,4 \\
\hline
\end{tabular}

As a result, at least 200 measurements were made for the studied area.

\section{Measurement results}

In accordance with the dependencies (1)-(7) and statistical processing of the obtained materials, the following data on the deformation modulus, the internal friction angle, the deformation modulus, and the soil density were obtained. In addition, the nature of soil moisture changes was analyzed. It is found that the highest percentage of moisture is achieved at a minimal height above sea level. This value is measured on the bank of the Ulynovka river.

Thus, depending on the soil moisture, its main parameters were of the following values, shown in table 2.

Table 2. Physical and mechanical characteristics of the soil.

\begin{tabular}{|c|c|c|c|c|c|}
\hline $\begin{array}{c}\text { Nature of the } \\
\text { area }\end{array}$ & $E_{\mathrm{y}}, \mathrm{N} / \mathrm{sm}^{2}$ & $C, \mathrm{kPa}$ & $\varphi$ & $\rho, \mathrm{g} / \mathrm{cm}$ & $\mathrm{W}, \%$ \\
\hline $\begin{array}{c}\text { with low } \\
\text { moisture }\end{array}$ & 15,6 & 13,9 & 14,8 & 1,1 & 0,35 \\
\hline $\begin{array}{c}\text { with average } \\
\text { moisture }\end{array}$ & 15,5 & 13,9 & 14,8 & 1,14 & 9,9 \\
\hline $\begin{array}{c}\text { with high } \\
\text { moisture }\end{array}$ & 22,4 & 16,7 & 16,4 & 1,09 & 16,9 \\
\hline
\end{tabular}

The obtained values of physical and mechanical characteristics of the soil are sufficient to predict the mobility of vehicles and special MRCs for agricultural mechanization. In accordance with the works of the authors [5-7] it is possible to calculate the traction force and the movement resistance and, as a result, to predict the maneuverability of the vehicles in the given conditions, and to select the most rational parameters of the motion. 


\section{Conclusion}

The analysis of the necessity of using mobile robotic complexes for agriculture is carried out. Using them allows to increase productivity.

It is shown that one of the aspects of the effectiveness of the robotic complexes use in agriculture is the assessment of their mobility and the calculation of maneuverability. To do this, it is necessary to know the physical and mechanical characteristics of the main support surfaces.

Research was conducted on the typical surfaces of movement in the spring near the village of Belka in the Knyaginino district of the Nizhny Novgorod region. Examples of the obtained experimental data are given for one location.

The main physical and mechanical characteristics of the soil, namely the deformation modulus, the internal friction angle, the soil cohesion coefficient, its density and moisture are obtained.

In the future, it is planned to conduct similar studies for other typical areas throughout the spring-autumn period in order to determine the nature of changes of the studied parameters during this time.

The results of the given study have been obtained with financial support of the grants of the President of the Russian Federation № MD-226.2020.8.

\section{References}

1. GOST 5180-84 Soils. Laboratory methods for determination of physical characteristics.

2. Soil penetrometer PG-1. Passport and user manual (2010)

3. V. Makarov, V. Filatov, U. Vahidov, A. Kurkin, V. Belyakov Study of trafficability conditions of typical soils of coastal zones of Sakhalin Island (Russian Federation).Paper presented at the 19th International and 14th European-African Regional Conference of the ISTVS(2017)

4. A. Kurkin, V. Makarov, D. Zeziulin, P. Beresnev, V. Filatov, D. Porubov Study of coastal soil surfaces of Sakhalin Island.Paper presented at the 13th International MEDCOAST Congress on Coastal and Marine Sciences, Engineering, Manage-ment and Conservation, MEDCOAST 2017, 2,775-785 (2017)

5. Ya.S. Ageykin, N.S. Volskaya Dynamics of the wheeled vehicle when driving on an uneven ground surface.(MGIU, Moscow, 124, 2003)

6. Ya.S. Ageykin, N.S. Volskaya Theory of the vehicle.(MGIU, Moscow, 318, 2008)

7. Ya.S. Ageykin, N.S. Volskaya, I.V.Chichekin Passability of vehicles. (MGIU, Moscow, 275, 2010) 